\title{
Patrimonio, dinámicas culturales y construcción de las identidades en los Andes del centro-sur
}

\section{Thérèse Bouysse-Cassagne}

\section{(2) OpenEdition \\ 1 Journals}

Edición electrónica

URL: http://journals.openedition.org/bifea/5684

DOI: $10.4000 /$ bifea.5684

ISSN: 2076-5827

Editor

Institut Français d'Études Andines

Edición impresa

Fecha de publicación: 1 mayo 2005

Paginación: 134

ISSN: 0303-7495

\section{Referencia electrónica}

Thérèse Bouysse-Cassagne, « Patrimonio, dinámicas culturales y construcción de las identidades en los Andes del centro-sur », Bulletin de l'Institut français d'études andines [En línea], 34 (1) | 2005,

Publicado el 08 abril 2005, consultado el 10 diciembre 2020. URL : http://journals.openedition.org/ bifea/5684; DOI : https://doi.org/10.4000/bifea.5684

\section{(c) $(7)(9$}

Les contenus du Bulletin de l'Institut français d'études andines sont mis à disposition selon les termes de la licence Creative Commons Attribution - Pas d'Utilisation Commerciale - Pas de Modification 4.0 International. 


\title{
PATRIMONIO, DINÁMICAS CULTURALES Y CONSTRUCCIÓN DE LAS IDENTIDADES EN LOS ANDES DEL CENTRO-SUR
}

\author{
El coloquio, patrocinado por la Embajada de Francia, la Cooperación Regional Francesa, \\ el IFEA, el IRD y el Credal del CNRS, tuvo lugar en La Paz los días 23 y 24 de octubre de \\ 2004.
}

Participaron a esta reunión 15 arqueólogos, etnohistoriadores y directores de museos procedentes de Argentina, Bolivia, Chile, Perú, y Europa, compartiendo sus experiencias y sus últimas investigaciones, siendo la meta de esta reunión considerar a los Andes del centro sur como una unidad cultural que permite compartir problemáticas comunes.

La propuesta de este coloquio consistía, en efecto, en situar la historia en el interfaz de varias tradiciones historiográficas y de varios paises. La primera tarea asignada era, en efecto, precisar las influencias culturales y su modo de funcionamiento para todos los periodos considerados, así como los procesos, estructuras o instituciones, con el objetivo de resolver una de las ambigüedades fundamentales de los trabajos sobre temas identitarios y patrimonio: cierta tendencia a pensar en términos de grupos o naciones.

El primer día fue dedicado a intercambios y discusiones sobre los modos de gestión del patrimonio en los distintos países considerados y se discutió sobre la necesaria contribución de la investigación a la museografía. Igualmente, se subrayó el interés de la participación de los pueblos locales y de los gobiernos en esta gestión. De este primer intercambio se evidencia la idea de que en algunos países la conservación resulta mucho más dificultuosa y conflictuada que en otros donde las poblaciones locales están más educadas y sensibilizadas a los problemas planteados por la gestión patrimonial y sobre todo por las investigaciones.

La segunda jornada, concebida en torno a la idea de unidad cultural, permitió intercambios fructíferos. No solo se demostró la necesidad de una colaboración interdiciplinaria sino que se comprobó que los marcos fronterizos actuales no son pertinentes a la hora de plantear los marcos conceptuales que permiten comprender el pasado prehispánico en esta región.

Los etnohistoriadores plantearon la posibilidad de dos modelos de poblamiento alternativos al modelo de economía vertical: el primero acerca del pastoreo y el segundo de los recursos no renovables como las minas. Criticaron los conceptos de gestión del patrimonio desde la perspectiva que predominó a lo largo del siglo pasado y sigue vigente en algunos casos, y discutieron en torno al problema de enseñanza de la etnohistoria andina.

Tres ponencias de arqueólogos dieron lugar a una discusión sobre la continuidad de los modelos de enterramientos en chullpas en el altiplano y el norte chileno a lo largo del Intermediario Tardío, demostrando, de esta manera, la existencia de un verdadero patrón cultural compartido y de relaciones interculturales.

Nuevos hallazgos que pertenecen al Periodo Formativo en el norte chileno y el importante descubrimiento de un yacimiento cerámico en la isla de Pariti (Titicaca, época Tiwanaku) fueron igualmente el objeto de un animado debate.

La reunión concluyó con una moción dirigida a los gobiernos de Chile, Bolivia, Perú y Argentina acerca de la conservación del Patrimonio en los Andes del centro sur. 